\title{
Suspending Excipient
}

National Cancer Institute

\section{Source}

National Cancer Institute. Suspending Excipient. NCI Thesaurus. Code C42660.

Therapeutically inactive ingredient of pharmaceutical dosage form used to prevent aggregation of the active drug in liquid form, allowing uniform concentrations to be maintained for accurate dosing. 